\title{
The Correlation of Papanicolaou Smears and Clinical Features to Identify the Common Risk Factors for Cervical Cancer: a Retrospective and Descriptive Study From a Tertiary Care Hospital in Trinidad
}

\author{
Srikanth Umakanthan \\ University of the West Indies \\ Saudah Ghany ( $\sim$ saudah.ghany@my.uwi.edu ) \\ University of the West Indies \\ La Donna Gay \\ University of the West Indies \\ Tia Gilkes \\ University of the West Indies \\ Jamila Freeman \\ University of the West Indies \\ Andre Francis \\ University of the West Indies \\ Kyle Francis \\ University of the West Indies \\ Gabriel Gajadhar \\ University of the West Indies \\ Junea Fraser \\ University of the West Indies
}

\section{Research Article}

Keywords: Papanicolaou smears, epithelial cell abnormality, cervical cancer

Posted Date: January 12th, 2022

DOI: https://doi.org/10.21203/rs.3.rs-1189806/v1

License: @ (i) This work is licensed under a Creative Commons Attribution 4.0 International License. Read Full License 


\section{Abstract}

Background: Cervical cancer, the fourth most frequent cancer in women, is associated with the human papilloma virus (HPV). This study focuses on identifying any risk factors and clinical findings for abnormal cervical cytology and histopathology in relation to the Trinidad and Tobago population. Some risk factors include early age of first coitus, high number of sexual partners, high parity, smoking, and use of certain medications such as oral contraception. This study is aimed to identify the significance of Papanicolaou (pap) smears and to identify the common risk factors that contribute to the development of premalignant and malignant cervical lesions.

Method: A three-year retrospective, descriptive study of cervical cancer was conducted at the Eric Williams Medical Sciences Complex to assess the risk factors and clinical findings using cervical cytology and histopathology data of patients with premalignant lesions. The subject population included 215 female patients aged 18 years and older who had the following documented abnormal cervical cytology: (ASCUS), ASC-H, LSIL, HSIL, Atypical Glandular cells, HPV, Adenocarcinoma, Invasive Squamous Cell Carcinoma. Histopathology records were analysed for thirty-three of these patients. Patients' information were recorded on data collection sheets adapted from the North Central Regional Health Authority's cytology laboratory standardised reporting format request form (Appendix I).

Results and findings: The data were analysed via Statistical Package for Social Sciences (SPSS) software edition 23 using frequency tables and descriptive analysis. The sample mean age of the population was 36.7 years, first age of coitus was 18.1 years, number of sexual partners was 3.8 and number of live births was 2. LSIL was the most popular abnormal finding, $32.6 \%$, followed by HSIL, $28.8 \%$ and ASCUS, $27.4 \%$. Most histopathological reports resulted in CIN I and II.

Conclusion: The major risk factors observed for cytology abnormalities and premalignant lesions were early age of coitus, high number of sexual partners, and no use of contraception.

Patients mostly presented as asymptomatic despite obtaining abnormal cytology results. Hence, regular pap smear screening should continue to be highly encouraged.

\section{Background:}

Cervical cancer is ranked as the fourth most common female cancer worldwide. ${ }^{1}$ It is also estimated that most deaths ( $90 \%$ ) occurred in low- and middleincome nations. In the Caribbean, it is the second cause of death amongst females. ${ }^{2}$ Its mortality rate is thrice that of North America's and is estimated to increase by $45 \%$ by the year $2030 .{ }^{3}$ Taking this into account, screening programmes are at the forefront of early detection of patients who may develop cancer. Cervical screening guidelines for the Caribbean region recommend that at a minimum, $80 \%$ of women aged $25-50$ years who have ever engaged in sexual intercourse should be screened for precancerous cervical lesions. Additionally, women with an abnormal cervical smear result should have repeat cervical screening at consecutive intervals or gynaecological evaluation. ${ }^{4}$

Malignancy of the cervix are mainly of two histological types; the more common squamous cell carcinoma and a rarer form called adenocarcinoma. There are two types of screening programmes: opportunistic and comprehensive/organised screening programmes. With opportunistic screening, patients request a test to be performed for any reason whilst with comprehensive, large groups of women are persuaded to have the test performed to identify those who may be asymptomatic.

Trinidad and Tobago was ranked seventh in the Caribbean for mortality rates of cervical cancer $(10.8$ per 100,000$)$ and although there has been an increase in screening programmes in Trinidad and Tobago, there has not been a decrease in mortality rates. This can be attributed to the fact that Trinidad and Tobago does not have a formal cervical cancer screening programme that is applied across the board, instead, each regional health authority (RHA) is responsible for their screening programme.

Cervical cell abnormalities include squamous cell and glandular cell abnormalities. Squamous cell abnormalities include, Low- grade squamous intraepithelial lesions (LSIL), of High- grade squamous intraepithelial lesions (HSIL), Atypical squamous cells of undetermined significance (ASCUS), Atypical squamous cells cannot exclude HSIL (ASC-H) and invasive squamous cell carcinoma. Glandular cell abnormalities include Atypical glandular cells and adenocarcinoma. ${ }^{5}$ These cellular abnormalities are identified in satisfactory specimens obtained from cervical samples during screening programmes or following symptomatic clinical evaluation of cervical pathology diagnosis. ${ }^{6}$

In Trinidad and Tobago, the screening programmes are conducted mainly to identify early premalignant cervical lesions through Papanicolaou smears (pap) smears in females above 18 years and continue until the age of 65 years. ${ }^{2}$ Since cervical cancer is mostly caused by Human Papilloma Virus (HPV), a sexually transmitted disease, the screening programmes usually target populations with low socio-economic regions. ${ }^{7}$ Patients with comorbidities, positive family history for cervical and related cancers, unsafe sexual practices and females with symptomatic cervical lesions add on to the high risk categories. ${ }^{8}$

The aims of our study were as follows: 1 . to identify premalignant and malignant cervical neoplasms using pap smears; 2 . to correlate its significance with identifiable risk factors and clinical features; and 3. to correlate the cytological findings with histopathology diagnosis.

This study further provides and establishes the significance of pap smears in screening programmes and aid in efforts for prevention, early diagnosis and successful management of cervical cancers.

\section{Methods:}


This retrospective and descriptive study comprised of screening of 6,208 pap smears using standard cervical cytology protocol over a three-year period. The selection criteria consisted of patients who underwent pap smear examinations at Mt. Hope Women's Hospital (MHWH) and health centres of the NCRHA and had abnormal cytology results. Among these, 215 cases were identified with cervical cytology abnormalities and were further evaluated for patient clinical and histopathology information from medical records department, which included: patient demographics, risk factors, medical and sexual history, family history, clinical findings and histopathology diagnosis. Histopathological correlations were performed on 33 traceable cases. The data obtained was analysed with the descriptive data analysis Statistical Package for the Social Sciences (SPSS) version 21 Premium. Descriptive data analysis included calculations of central tendencies: means, medians, modes, ranges and other estimates of the demographic of the sample were generated. Further analysis using frequencies and percentages were utilized to determine the risk factors of abnormal cervical cytology and histopathology.

\section{Results:}

As seen in Table 1 (end of manuscript), most of the sample population, 66 patients (30.7\%) came from the age group of $34-41$ years old. Most of the patients, 136 (63.3\%), were Afro-Trinidadians, 33 (15.3\%) were Indo-Trinidadians and 46 (21.4\%) were of mixed ethnicity. Most patients in the population were single, 92 (42.8\%). Majority of the patients hailed from Eastern Trinidad, 98 (45.6\%) and Northern Trinidad, 77 (35.8\%).

Table 1

Frequency table showing a summary of the socio-demographic characteristics of the sample population.

\begin{tabular}{|c|c|c|c|}
\hline \multicolumn{2}{|c|}{ DEMOGRAPHIC CHARACTERISTICS } & \multirow{2}{*}{$\begin{array}{l}\text { FREQUENCY } \\
30\end{array}$} & \multirow{2}{*}{$\begin{array}{l}\text { PERCENTAGE (\%) } \\
14.0\end{array}$} \\
\hline AGE GROUP (years) & $18-25$ & & \\
\hline & $26-33$ & 60 & 27.9 \\
\hline & $34-41$ & 66 & 30.7 \\
\hline & $42-49$ & 38 & 17.7 \\
\hline & $50-57$ & 14 & 6.5 \\
\hline & $58-65$ & 5 & 2.3 \\
\hline & Over 65 & 2 & 0.9 \\
\hline Total & & 215 & 100.0 \\
\hline \multirow[t]{3}{*}{ ETHNICITY } & African & 136 & 63.3 \\
\hline & Indian & 33 & 15.3 \\
\hline & Mixed & 46 & 21.4 \\
\hline Total & & 215 & 100.0 \\
\hline \multirow[t]{7}{*}{ MARITAL STATUS } & Single & 92 & 42.8 \\
\hline & Married & 50 & 23.3 \\
\hline & Separated & 5 & 2.3 \\
\hline & Divorced & 15 & 7.0 \\
\hline & Widowed & 6 & 2.8 \\
\hline & Common Law & 44 & 20.5 \\
\hline & Unspecified & 3 & 1.4 \\
\hline Total & & 215 & 100.0 \\
\hline \multirow[t]{5}{*}{ LOCATION } & Central & 31 & 14.4 \\
\hline & East & 98 & 45.6 \\
\hline & North & 77 & 35.8 \\
\hline & South & 3 & 1.4 \\
\hline & West & 6 & 2.8 \\
\hline Total & & 215 & 100.0 \\
\hline
\end{tabular}


Table 2

Measurement of central tendencies, standard deviation and minimum and maximum for numeric risk factors.

\begin{tabular}{|llllll|}
\hline Measure of central tendencies: & Age & First age of coitus & Number of sexual partners & Number of pregnancies & Number of live births \\
\hline Mean & 36.7349 & 18.1163 & 3.7907 & 2.9070 & 2.0140 \\
\hline Median & 36.000 & 18.0000 & 3.0000 & 3.0000 & 2.0000 \\
\hline Mode & 31.00 & 18.00 & 1.00 & 0.00 & 0.00 \\
\hline Std. Deviation & 10.13919 & 3.19323 & 3.47594 & 2.46863 & 1.74944 \\
\hline Minimum & 18.00 & 10.00 & 1.00 & 0.00 & 0.00 \\
\hline Maximum & 81.00 & 30.00 & 23.00 & 13.00 & 8.00 \\
\hline
\end{tabular}

From Table 2, notable risk factors are: the sample mean age for first sexual intercourse was $18.1+/-3.2$ years, minimum age was 10 years and the maximum was 30 years. The sample mean for sexual partners was $3.8+/-3.5$. The minimum was 1 partner and the maximum were 23 partners. The sample mean number of live births was $2.0+/-1.8$ whilst the sample mean number of pregnancies was $2.9+/-2.5$.

The majority of patients, $132(61.4 \%)$ did not have any noted medical history. However, 83 (38.6\%) had certain comorbidities or an illness. 25 (11.6\%) had hypertension, 11 (5.1\%) had diabetes, 11 (5.1\% had HIV). For the HIV patients, the number of sexual partners ranged from 2-23 and the first age of coitus ranged from 10-20 years old. Other noteworthy mentions are: 17 patients had asthma, 6 patients had lupus and 2 patients had a history of cervical cancer. 14 patients (6.5\%) also admitted to smoking.

Table 3

Showing the sample population who had a family history of cancer.

\begin{tabular}{|lll|}
\hline Family History of Cancer & Frequency & Percentage (\%) \\
\hline Has a family history of cancer & 82 & 38.5 \\
\hline Does not have a family history of cancer & 133 & 61.5 \\
\hline Total & 215 & 100.0 \\
\hline
\end{tabular}

Table 4

Use of contraception in the sample population

\begin{tabular}{|lll|}
\hline Use of contraception: & Frequency & Percentage (\%) \\
\hline Uses contraception & 82 & $38.1 \%$ \\
\hline Does not use contraception & 133 & $61.9 \%$ \\
\hline Total & 215 & 100.0 \\
\hline
\end{tabular}

Table 3 shows that 133 (61.5\%) did not have a family member who had cancer while 82 (38.5\%) did. Of those who did, $6.5 \%$ of family members had cervical cancer of which were mostly secondary relations, $14 \%$ had another type of female reproductive cancer such as breast, ovarian and uterine and $79.5 \%$ had another type of cancer such as stomach, pancreatic, prostate and lung. Table 4 elaborates that most patients did not use any form of contraceptive, 82 (61.9 $\%$ ) whilst $82(38.1 \%)$ used.

From Table 5 (see table at end of manuscript), most patients exhibited normal bleeding, 177 (82.3\%), whilst 38 (17.7\%) had abnormal bleeding. Majority of patients, 147 (68.4\%), did not have any discharge. The clinical appearance of the vagina and vulva were normal for most patients, 214 (99.5\%) and 213 $(99.1 \%)$ respectively. The cervix was normal for $170(79.1 \%)$ of patients, $36(16.7 \%)$ had contact bleed, $3(1.4 \%)$ had erosion, 3 (1.4\%) had chronic cervicitis and $1.4 \%$ had a polyp. These were incidental clinical findings during the screening programme. 
Table 5

Frequency table showing a summary of clinical findings of the sample population.

\begin{tabular}{|c|c|c|c|}
\hline CLINICAL CHARACTERISTICS & RESULTS & FREQUENCY & PERCENTAGE (\%) \\
\hline \multirow[t]{2}{*}{ Abnormal Bleeding } & Normal & 177 & 82.3 \\
\hline & Abnormal & 38 & 17.7 \\
\hline Total & & 215 & 100.0 \\
\hline \multirow[t]{2}{*}{ Appearance of Vagina } & Normal & 214 & 99.5 \\
\hline & Abnormal & 1 & 0.5 \\
\hline Total & & 215 & 100.0 \\
\hline \multirow[t]{2}{*}{ Appearance of Vulva } & Normal & 213 & 99.1 \\
\hline & Abnormal & 2 & 0.9 \\
\hline Total & & 215 & 100.0 \\
\hline \multirow[t]{5}{*}{ Appearance of Cervix } & Normal & 170 & 79.1 \\
\hline & Contact Bleed & 36 & 16.7 \\
\hline & Erosion & 3 & 1.4 \\
\hline & Chronic Cervicitis & 3 & 1.4 \\
\hline & Polyp & 3 & 1.4 \\
\hline Total & & 215 & 100.0 \\
\hline \multirow[t]{6}{*}{ Presence of Discharge } & None & 147 & 68.4 \\
\hline & Purulent & 1 & 0.5 \\
\hline & Leukorrhea & 25 & 11.6 \\
\hline & Frank Blood & 5 & 2.3 \\
\hline & Serosanguineous & 2 & 0.9 \\
\hline & Other & 35 & 16.3 \\
\hline Total & & 215 & 100.0 \\
\hline
\end{tabular}

Table 6

Frequency of cytology findings from pap smears in the sample population. All samples are valid.

\begin{tabular}{|lll|}
\hline RESULTS & FREQUENCY & PERCENTAGE (\%) \\
\hline ASCUS & 59 & 27.4 \\
\hline HPV & 11 & 5.1 \\
\hline ATYPICAL GLANDULAR CELL & 7 & 3.3 \\
\hline LSIL & 70 & 32.6 \\
\hline ASC-H & 5 & 2.3 \\
\hline HSIL & 62 & 28.8 \\
\hline INVASIVE SQUAMOUS CELL CARCINOMA & 1 & 0.5 \\
\hline ADENOCARCINOMA & 0 & 0 \\
\hline TOTAL & 215 & 100 \\
\hline
\end{tabular}

Table 6 shows that the most common cytological finding was LSIL which was found in 70 (32.6\%) of patients. This was followed by HSIL, seen in 62 (28.8\%) of patients and ASCUS, seen in 59 (27.4\%). There were 11 (5.1\%) of cases with HPV and no Adenocarcinomas were found. 
Table 7

Frequency showing the histopathological findings from patients' cervical biopsies.

\begin{tabular}{|lll|}
\hline Grade of Cervical Intraepithelial Lesion & Frequency & Percentage \\
\hline CIN I & 12 & 36.4 \\
\hline CIN II & 11 & 33.3 \\
\hline CIN III & 9 & 27.3 \\
\hline Invasive Squamous Cell Carcinoma reported & 1 & 3.0 \\
\hline Total & 33 & $100 \%$ \\
\hline
\end{tabular}

Out of the 33 patients whose histopathology reports were accessible. Table 7 elaborates that 12 (36.4\%) of these patients had CIN I, 11 (33.3\%) had CIN II, 9 (27.3\%) had CIN III and there was one case of Invasive Squamous Cell Carcinoma (SCC) reported, 3.0\%

\section{Discussion:}

In the Caribbean, there are few studies on cervical cancer and its risk factors. Some of these risk factors are exposure to Human Papilloma Virus (HPV), specifically types 16 and 18, older age at diagnosis, decrease in accessibility to contraception, first sexual encounter before 20 years of age, high parity, smoking, oral contraceptive pill usage exceeding 5 years, family history of cervical cancer and immune-depression and systemic disease. ${ }^{2,9}$

In our study, most patients were between the ages of 18 and 41 years which coincided with a previous report of $15-44$ years. ${ }^{10}$ Afro-Trinidadians were the majority, representing $63.6 \%$ of the sample population. This trend was also seen in the United States of America where African American and Latina populations could not afford routine pap smear screening. ${ }^{11}$ However, in Trinidad, pap smears are done free of charge at all health centres and some hospitals. Therefore, a possible reason for the high number of Afro-Trinidadians in this study may be due to the region of sampling as our sample site, captured the population from the Eastern and Northern areas of Trinidad where the Afro-Trinidadian population is high.

Findings in our study revealed that most of the women were single (42.8\%). It is therefore more likely that these individuals would have had more sexual partners when compared to their married and common-law counterparts and hence an increased risk of contracting HPV.

There are no conclusive links with medical history and cervical cancer. The high number of hypertensive and diabetic patients in our sample can be attributed to the fact that they are the most prevalent lifestyle diseases in Trinidad.

However, Blumenfeld (1994) found that women with systemic lupus erythematosus (SLE) had higher incidences of cervical pathologies when compared to non-SLE women. ${ }^{12}$ Six SLE cases were found in our study and $5.1 \%$ of our sample population were HIV positive. An immune-deficient system is less efficient in protecting the body from HPV and is more susceptible to cell abnormalities. HPV, a sexually transmitted disease has a strong link with cervical cancer. One study (Burd 2003) even noted that such association was greater than the association between smoking and lung cancer. HPV types 16 and 18 are known for predominantly infecting the cervix resulting in atypical growth of cells and it has been found in almost all (99.7\%) cervical cancer cases. ${ }^{13}$

There was no significant association between one's family medical history of cervical cancer and a woman's predisposition in acquiring the disease. This disease, like many other cancers is multifactorial and hence it should be noted that lifestyle choices have a greater influence. However, familial aggregation is possible from genetic susceptibility, shared environmental exposure and shared lifestyle practice among family members. ${ }^{14}$ Genetic susceptibility includes genes that make patients more vulnerable to persistent HPV infections including those that regulate immunity and susceptibility. ${ }^{15}$ It is therefore of paramount importance that women are conscious of their medical, social and sexual behaviour. ${ }^{9}$

One such social behaviour is smoking, which has been shown to be a cofactor for cervical cancer. ${ }^{16}$ Our study showed that only $6.5 \%$ of the patients smoked. This low percentage can be because approximately only $11 \%$ of the female population in Trinidad smokes. ${ }^{17}$

The length of oral contraceptive usage was not specified and/or stated in data collection by participants, therefore no relationship was found between its use and premalignant cervical lesions. However, most women indicated no use of contraception which therefore increases their susceptibility in acquiring sexually transmitted infections such as HIV and HPV. One study (Moreno et al, 2002) found that long term use of oral contraceptives increased the risk of cervical cancer up to four-fold. ${ }^{18}$ In a systematic review done by Smitha et al (2020) it was concluded that the longer the use of oral contraceptives, the greater their risk of developing cervical cancer. Additionally, risk among specific histologic types of cervical carcinoma were evaluated separately and it was found that the risk was higher for those with adenocarcinoma compared to squamous cell carcinoma. ${ }^{19}$ A study done by Parazzini et al (1998) suggests that Oral Contraceptives may have a late stage (promoter) effect on cervical carcinogenesis and thus have public health implications, since the incidence of invasive cervical cancers is low at young ages, when Oral contraceptive use is more common and increases during middle age.. ${ }^{20}$ Another study by Parazzini et al (1989) found that the risk of intraepithelial neoplasia was lowered with use of barrier methods of contraception. ${ }^{21}$

Boyles (2007) noted that the use of oral contraceptives for at least five years doubled the incidence of cervical cancer. ${ }^{22}$ However, this can be viewed as a double-edged sword because while high parity in women was observed to be a risk factor, taking the oral contraceptives to decrease parity was also a risk 
factor. In our study, the average live births were 2 and therefore this could not conclusively link increasing parity rates in women to the development of premalignant lesions.

In this study, it was seen that most of our patients had coitarche at 20 years of age. Early onset of coitus can lead to increased exposure to HPV, increased number of sexual partners in one's lifetime and a higher likelihood of pregnancy. A comparison study (Louie KS, 2009) showed that females who had coitarche before 16 years of age were approximately two times more likely to get invasive cervical cancer than those who initiated sexual intercourse after age $21 .{ }^{23}$ This link was further strengthened among parous women than those who were nulliparous. Shepherd et.al (2000) in a systematic review also noted that women who initiated sexual intercourse at or around age 15 were twice as likely to contract HPV than those who commenced after 20 years of age. ${ }^{24}$

Most women had normal appearances of the cervix, vagina and vulva, no discharge and they reported normal bleeding which illustrated the asymptomatic nature in the early stages of cervical cancer.

The pap smear findings in our study revealed a proportional predominance of LSIL, HSIL and ASCUS. Immunocompetent women with LSIL should be tested for HPV DNA (Deoxyribonucleic Acid) in 12 months duration. If HPV DNA is positive, they should be managed appropriately and followed up either for spontaneous regression or for severe progression into more atypical forms (ASCUS, ASC-H, HSIL, SCC) ${ }^{25}$ If repeated smears in 12 months show abnormal findings, they should be referred for colposcopic biopsy, as they are at a higher risk of progression into more atypical or malignant forms. ${ }^{26}$ In patients who had LSIL with previous normal smears, they are advised for a follow up smear in 6-12 months and are managed according to the pap smear results in the follow up test. If the follow up smear shows ASCUS or higher grade of atypia, then colposcopy is advised; if the result is normal, then they are advised to return for annual screening. ${ }^{27}$

Cytological findings except HSIL cannot stand alone to confirm cervical cancer. They simply inform the gynaecologist that there is a presence of abnormal cells and such abnormalities must undergo biopsies or colposcopies for diagnosis. ${ }^{28}$

Of the 33 patients who had histopathological testing, 12 had CIN I, this develops slowly and most cases regress on its own. Treatment is not required but rather the condition will be placed under observation. 10 patients had CIN II and 8 had CIN III which indicate they possess high progression risks and therefore treatment is necessary. However, studies have shown that $50 \%$ of $\mathrm{CIN} \mathrm{II} \mathrm{cases} \mathrm{have} \mathrm{regressed} \mathrm{on} \mathrm{its} \mathrm{own.}{ }^{29}$ This information echoes and magnifies the importance of early screening which can lead to early detection and early treatment.

Locally, there are free cervical screening programmes in the public health sector, these include cytology, HPV DNA testing and visual inspection of acetic acid (VIA). Although HPV DNA testing has advantages over cytology and VIA, cytology continues to be mainly used. The target population, 25- 49 years, in 2009 and 2010 comprised of $11 \%$ and $13.2 \%$ respectively in reference to the total number of pap smears done. ${ }^{4}$ It was found that more than $50 \%$ of these patients never sought follow up visits as recommended for a repeated Pap Smear. This showed adequate coverage was not achieved by the Regional Health Authority for women with abnormal pap smears in 2009 and 2010. 4

As of 2013, Trinidad and Tobago's Ministry of Health expanded the National Immunization Programme with the introduction of the Human Papillomavirus Vaccination (HPV). The communication strategy plan included conducting first-sensitization sessions with the media personnel, HPV vaccination promotional posters and brochures, and numerous training and sensitization sessions for healthcare workers, Primary and Secondary school staff and parents and religious groups.

The HPV vaccination of pre-adolescent girls is delivered as a school-based programme. Currently, HPV vaccinations are done free of charge by appointment at all Health Centres on days scheduled for immunization and there are also vaccination and pap smear drives. ${ }^{(30)}$

Sealy et al (2020) explored barriers and facilitators that affected the acceptance of the HPV vaccine by mothers of adolescents in Trinidad and Tobago. Three major themes emerged: a) cervical cancer and vaccine knowledge, b) barriers to uptake, and c) rephrasing the vaccine strategy. Data indicated that no widespread strategies to educate the population about the vaccine had occurred. Barriers to uptake of the vaccine were related to a lack of information on the efficacy and safety of HPV vaccines. Parents were unaware that the HPV caused cervical cancer. Hence, the study proposed that physicians and other health professionals be used to deliver targeted messages to parents and adolescents to improve uptake of the vaccine. ${ }^{(31)}$

Compared to other Caribbean countries, Trinidad and Tobago was noted for having more human and infrastructural resources with a population-based cancer registry. However, it lacks vital components such as a programme evaluation, a cervical cancer policy, a programme manager for cervical cancer and a budget for cervical cancer programme. There is also no information system for follow-up and no Civil Society Organization to cooperate in cervical cancer communication, social mobilization and advocacy. ${ }^{(32)}$

\section{Limitations}

The National Cancer Registry's lack of data for the years after 2011. Additionally, there is no no formal Screening Register in Trinidad and Tobago which meant that data had to be collected from the Cytology Lab's Logbook. Only 33 traceable histopathological reports were found from the RHA records.

If more than one regional health authority been used, the sample population would have had more diversity and the value of data trends would be strengthened.

Our sample population included patients from health centres under NCRHA, cytology request forms varied among the different health centres. Forms that excluded important information such as number of sexual partners and first age of coitus had to be omitted, hence limiting our sample size.

Page $7 / 10$ 


\section{Conclusion:}

The major risk factors observed for cytology abnormalities and premalignant lesions were early age of coitus, high number of sexual partners, and no use of contraception and patients mostly presented as asymptomatic despite obtaining abnormal pap smear results. This reiterates the importance of pap smear tests as a screening tool for cervical cancer for all eligible females.

\section{List Of Abbreviations:}

ASC-H- Atypical squamous cells cannot exclude HSIL

ASCUS- Atypical Squamous Cells of Undetermined Significance

CIN- Cervical Intraepithelial Neoplasia

DNA- Deoxyribonucleic Acid

ERHA- Eastern Regional Health Authority Virus

HIV-Human Immunodeficiency Virus

HPV- Human Papilloma Virus

HSIL- High-Grade squamous intraepithelial lesion

LSIL- Low-Grade Squamous Intraepithelial Lesion

MHWH-Mt. Hope Women's Hospital

NCRHA-North Central Regional Health Authority

PAP smear/s- Papanicolaou Smear/s

RHA-Regional Health Authority

SCC- Squamous Cell Carcinoma

SLE- Systemic Lupus Erythematosus

SPSS-Statistical Package for the Social Sciences

VIA- visual inspection of acetic acid

\section{Declarations:}

\section{Ethics approval and consent to participate}

Ethical approval was granted by the Ethics Committee of the University of the West Indies, St. Augustine (CEC 789/11/18) and The North Central Regional Health Authority (NCRHA). All methods were carried out in accordance with the Declaration of Helsinki and the relevant guidelines and regulations of the University of the West Indies, St Augustine and North Central Regional Health Authority of Trinidad and Tobago. Approval by both committees were granted prior to commencing this retrospective study.

\section{Consent for publication}

This was a retrospective study and no patients were directly contacted. Patient records were obtained from medical records after obtaining ethical clearance from both the University of the West Indies and the North Central Regional Health Authority and consent for publication was given from both committees.

\section{Consent for participation}

This was a retrospective study and no patients were directly contacted. Patient records were obtained from medical records after obtaining ethical clearance from both the University of the West Indies and the North Central Regional Health Authority. The patients were deidentified, hence, patient consent was not warranted and this was approved by both committees.

\section{Availability of data and materials}

The datasets generated and/or analysed during the current study are not publicly available to preserve patients' confidentialities but are available from the corresponding author on reasonable request.

\section{Competing interests}


Authors declare no competing interests.

The authors declare that they have no known competing financial interests or personal relationships that could have appeared to influence the work reported in this paper.

\section{Funding}

No specific grant for this research from any funding agency in the public, commercial or not-for-profit sector was provided.

\section{Authors' contributions}

Dr. Srikanth Umakanthan contributed to the conception, design of the work, revision and final version. Andre Francis, Gabriel Garjadar, Jameela Freeman, Junea Fraser, Kyle Francis, La Donna Gay Saudah Ghany and Tia Gilkes contributed to the methodology, data curation, formal analysis, visualization, interpretation and writing and original drafting. Dr. Srikanth Umakanthan, Andre Francis, Jameela Freeman, Junea Fraser, La Donna Gay and Saudah Ghany were involved in revising the final version and granting final approval for the article to be submitted for publication.

\section{Acknowledgements}

Our special thanks are extended to the technicians and staff at the Cytology Laboratory Department and Anatomical Pathology Unit at Eric Williams Medical Sciences Complex. We would also like to thank the Medical Records Section at Mt. Hope Women's Hospital for offering guidance in obtaining data for this research and accommodating us.

\section{References:}

1. World Health Organization. https://www.who.int/cancer/prevention/diagnosis-screening/cervical-cancer/en/ Cervical cancer. Accessed 11 July 2019.

2. Llanos A, Warner W, Luciani S, Lee T, Bajracharya S, Slovacek S et al. Gynecologic cancer mortality in Trinidad and Tobago and comparisons of mortalityto-incidence rate ratios across global regions. Cancer Causes \& Control [Internet]. 2017 [cited 2019 Jul 11];28(11):1251-1263. Available from:_https://pubmed.ncbi.nlm.nih.gov/28917021/_DOI:10.1007/s10552-017-0961-4

3. Pan American Health Organization. https://www.paho.org/en/topics/cervical-cancer. Cervical Cancer - PAHO/WHO Accessed 11 July 2019.

4. Lynch-George G, Maharaj R. Cervical Smears at Public Health Centres in Eastern Trinidad: Coverage and Follow-up, 2009-2010. West Indian Medical Journal [Internet] 2015 Jul 28 [cited 2019 July] Available from https://www.ncbi.nlm.nih.gov/pmc/articles/PMC4663954/ DOI:10.7727/wimj.2013.295

5. Comprehensive Cervical Cancer Control: A Guide to Essential Practice. 2nd edition. Geneva: World Health Organization; 2014. Annex 4, Cancer and precancer classification systems. Available from: https://www.ncbi.nlm.nih.gov/books/NBK269605/

6. Safaeian M, Solomon D, Castle PE. Cervical cancer prevention-cervical screening: science in evolution. Obstet Gynecol Clin North Am. 2007;34(4):739-ix. doi:10.1016/j.ogc.2007.09.004

7. Chan CK, Aimagambetova G, Ukybassova T, Kongrtay K, Azizan A. Human Papillomavirus Infection and Cervical Cancer: Epidemiology, Screening, and Vaccination-Review of Current Perspectives. J Oncol. 2019;2019:3257939. Published 2019 Oct 10. doi:10.1155/2019/3257939

8. Cofie LE, Hirth JM, Wong R. Chronic comorbidities and cervical cancer screening and adherence among US-born and foreign-born women. Cancer Causes Control. 2018;29(11):1105-1113. doi:10.1007/s10552-018-1084-2

9. Makuza J, Nsanzimana S, Muhimpundu M, Pace L, Ntaganira J, Riedel D. Prevalence and risk factors for cervical cancer and pre-cancerous lesions in Rwanda. Pan African Medical Journal. [Internet]. 2015 Sep [cited 2019 July 08];22:26. Available from: https://www.ncbi.nlm.nih.gov/pmc/articles/PMC4662515/ DOI: 10.11604/pamj.2015.22.26.7116

10. Bruni L, Albero G, Serrano B, Mena M, Gómez D, Muñoz J, Bosch FX, de Sanjosé S. ICO/IARC Information Centre on HPV and Cancer (HPV Information Centre). Human Papillomavirus and Related Diseases in Trinidad \& Tobago. 2019 [cited 2019 July 20] Available from: https://hpvcentre.net/statistics/reports/TTO.pdf

11. HPV-Associated Cervical Cancer Rates by Race and Ethnicity. https://www.cdc.gov/cancer/hpv/statistics/cervical.htm. Accessed on July 2019.

12. Blumenfeld Z, Lorber M, Yoffe N, Scharf Y. Systemic lupus erythematosus: predisposition for uterine cervical dysplasia. Lupus [Internet]. 1994 Feb [cited 2019 July 08];3(1):59-61. Available from: https://pubmed.ncbi.nlm.nih.gov/8025589

DOI: $10.1177 / 096120339400300112$

13. Burd, E., 2003. Human papillomavirus and cervical cancer. Clin Microbiol Rev. [online], 16(1):1-17. Available from: https://pubmed.ncbi.nlm.nih.gov/12525422/ [Accessed 20 Jul 2019]. DOI: 10.1128/CMR.16.1.1-17.2003

14. de M. Zelmanowicz, A. and Hildesheim, A., 2004. Family history of cancer as a risk factor for cervical carcinoma: a review of the literature. [online]. Available from:

https://www.researchgate.net/publication/233658783_Family_history_of_cancer_as_a_riskfactor_for_cervical_carcinoma_A_review_of_the_literature. [Accessed 19 Jul 2019]. DOI: 10.1179/095741904225005115

15. Liu, L., Yang, X., Chen, X., Kan, T., Shen, Y., Chen, Z. and Hu, Z., 2011. Association between TNF-a polymorphisms and cervical cancer risk: a meta-analysis. Molecular Biology Reports [online], 39 (3), 2683-2688. Available from: https://pubmed.ncbi.nlm.nih.gov/21670964/

[Accessed 19 July 2019]. DOI: 10.1007/s11033-011-1022-9

16. Fonseca-Moutinho, J., 2011. Smoking and Cervical Cancer. [online]. ISRN Obstet Gynecol. Available from: https://www.ncbi.nlm.nih.gov/pmc/articles/PMC3140050/ [Accessed 19 July 2019]. DOI: 10.5402/2011/847684

Page 9/10 
17. Blanco A, Sandoval R, Caixeta R, Gonzales J. Trinidad and Tobago Tobacco Control Report. [Internet]. 2011. Available from: https://www.paho.org/hq/dmdocuments/2012/TRINIDAD-TOBAGO-CR-web.pdf

18. Moreno V, Bosch F, Muñoz N, Meijer C, Shah K, Walboomers J et al. Effect of oral contraceptives on risk of cervical cancer in women with human papillomavirus infection: the IARC multicentric case-control study. The Lancet [Internet]. 2002 Mar [cited 2019 Mar 16];359(9312):1085-1092. Available from: https://pubmed.ncbi.nIm.nih.gov/11943255/ DOI: 10.1016/S0140-6736(02)08150-3

19. Smitha A, Busa V, Labani S. Oral contraceptives use and risk of cervical cancer-A systematic review \& meta-analysis. Eur J Obstet Gynecol Reprod Biol [Internet]. 2020 [cited 2020 Feb 8] Available from: https://pubmed.ncbi.nlm.nih.gov/32114321/ DOI:10.1016/j.ejogrb.2020.02.014

20. Parazzini F, Chatenoud L, La Vecchia C, Chiaffarino F, Ricci E, Negri E. Time since last use of oral contraceptives and risk of invasive cervical cancer. European Journal of Cancer. [Internet].1998 May [cited 2020 Feb 6];34(6):884-888. Available from: https://pubmed.ncbi.nlm.nih.gov/9797702/ DOI: 10.1016/s0959-8049(97)10139-3

21. Parazzini F, Negri E, La Vecchia C, Fedele L. Barrier methods of contraception and the risk of cervical neoplasia. Contraception. An International Reproductive Health Journal [Internet].1989 Nov [cited 2020 Feb 8];40(5):519-530. Available from:https://www.contraceptionjournal.org/article/00107824(89)90125-X/pdf DOI: 10.1016/0010-7824(89)90125-x

22. Boyles S, The Pill Raises Cervical Cancer Risk. WebMD. [Internet]. 2007 November. Available from: https://www.webmd.com/sex/birthcontrol/news/20071108/pill-raises-cervical-cancer-risk

23. Louie KS, de Sanjose S, Diaz M, Castellsagué X, Herrero R, Meijer CJ, et al. Early age at first sexual intercourse and early pregnancy are risk factors for cervical cancer in developing countries [Internet]. British journal of cancer. Nature Publishing Group; 2009 [cited 2021 Jan 28 ]. Available from: https://www.ncbi.nlm.nih.gov/pmc/articles/PMC2670004/\#: :text=Early\%20age\%20at\%20first\%20sexual\%20intercourse\%20(AFSI)\%20has\%20been\%20; DOI: $10.1038 /$ sj.bjc. 6604974

24. Shepherd J, Peersman G, Weston R and Napuli I, Cervical cancer and sexual lifestyle: a systematic review of health education interventions targeted at women. [Internet]. 2000 December 01. Health Education Research. Available from: https://doi.org/10.1093/her/15.6.681

25. Hull R, Mbele M, Makhafola T, et al. Cervical cancer in low and middle-income countries. Oncol Lett. 2020;20(3):2058-2074. doi:10.3892/ol.2020.11754

26. Lau S, Franco EL. Management of low-grade cervical lesions in young women. CMAJ. 2005;173(7):771-774. doi:10.1503/cmaj.05056158-2074, 2020

27. Mehmetoglu HC, Sadikoglu G, Ozcakir A, Bilgel N. Pap smear screening in the primary health care setting: A study from Turkey. N Am J Med Sci. 2010;2(10):467-472. doi:10.4297/najms.2010.2468

28. Crum C, Warner K H. Cervical and vaginal cytology: Interpretation of results (Pap test report) Uptodate.com. https://www.uptodate.com/contents/cervicaland-vaginal-cytology-interpretation-of-results-pap-test-report. Accessed on July 2019. [Internet].

29. Wright, J. Cervical intraepithelial neoplasia: Management of low-grade and high-grade lesions Uptodate.com. https://www.uptodate.com/contents/cervical-intraepithelial-neoplasia-management-of-low-grade-and-high-grade-lesions. Accessed on July 2019. [Internet].

30. Tirso, C., 2021. PAHO/WHO / (February) Trinidad and Tobago Rolls Out HPV Vaccination Programme for Adolescent Girls. Pan American Health Organization. https://www3.paho.org/hq/index.php?option=com_content\&view=article\&id=8336:2013-february-trinidad-tobago-rolls-out-hpv-vaccinationprogramme-adolescent-girls\&ltemid=39440\&lang=en. Accessed on 10 December 2021. [online] Pan American Health Organization / World Health Organization.

31. Sealy, D., Modeste, N. and Dyett, P., 2021. Barriers and facilitators to the HPV vaccine among mothers of adolescent girls: a qualitative study conducted in Trinidad and Tobago. [online] Available at: <https://pubmed.ncbi.nlm.nih.gov/33272144/> [Accessed 10 December 2021]. DOI: 10.1080/03630242.2020.1856295

32. Martin, D., Luciani, S. and Prieto, E., 2013. Situational Analysis of Cervical Cancer Prevention and Control in the Caribbean. Available from:https://www.paho.org/hq/dmdocuments/2013/Caribbean-cxca-situation-analysis-2013.pdf 